\title{
Sistemas de dessecação em áreas de trigo no inverno e atividade residual de herbicidas na soja ${ }^{1}$
}

\section{Burndown programs in winter wheat crop and residual activity in soybean crop}

Antonio Mendes de Oliveira Neto ${ }^{2}$; Jamil Constantin ${ }^{3}$; Rubem Silvério de Oliveira Jr. ${ }^{3}$; Naiara Guerra $^{4}$; Guilherme Braga Pereira Braz ${ }^{4}$; Lélio Marcos Silva Vilela ${ }^{5}$; Lucas Von Pinho Botelho ${ }^{5}$; Lucas André Ávila ${ }^{5}$

Resumo - O sistema de cultivo praticado no inverno tem impacto direto na infestação de Conyza spp na safra seguinte. Desta forma, objetivou-se avaliar a eficiência da dessecação de manejo no controle de Conyza spp. em áreas cultivadas com trigo durante o inverno, bem como avaliar o efeito residual dos herbicidas no controle de plantas daninhas no início do ciclo da cultura da soja. $\mathrm{O}$ experimento foi conduzido em duas localidades durante os meses de novembro de 2010 a janeiro de 2011, no Rio Grande do Sul (Condor e Estação). Os tratamentos foram compostos por uma testemunha sem herbicida e por misturas em tanque de herbicidas. Todas as misturas continham glyphosate a $720 \mathrm{~g}$ e.a. ha ${ }^{-1}$. O glyphosate foi combinado com 2,4-D (402 g e.a. ha $\left.{ }^{-1}\right)$, diclosulam $\left(25,2\right.$ g i.a. ha $\left.{ }^{-1}\right)$, chlorimuron-ethyl $\left(10,20\right.$ e $25 \mathrm{~g}$ i.a. ha $\left.{ }^{-1}\right)$, e com chlorimuron + flumioxazin $\left(15+50 ; 20+50 ; 25+50 ; 15+60 ; 20+60\right.$ e $25+60$ g i.a. ha $\left.{ }^{-1}\right)$. Avaliou-se a porcentagem de controle da dessecação, a densidade de plantas daninhas por $\mathrm{m}^{2}$ e $\mathrm{o}$ estádio de desenvolvimento das plantas daninhas. As misturas de glyphosate com chlorimuron-ethyl + flumioxazin, chlorimuron-ethyl e diclosulam, independentemente das doses, foram eficazes para o controle de Conyza spp. na dessecação. Os tratamentos com glyphosate + chlorimuron-ethyl + flumioxazin foram os únicos tratamentos eficazes na supressão do crescimento de novos fluxos de E. heterophylla em Condor. Todas as misturas contendo chlorimuron-ethyl + flumioxazin, chlorimuron-ethyl ou diclosulam suprimiram o desenvolvimento inicial de Digitaria spp., Sida rhombifolia e Ipomoea triloba em Estação.

Palavras-chaves: buva, Conyza spp., eficiência, mistura em tanque

Abstract - The winter field system has impacted the Conyza spp. infestation on the next Field. Thus, the aim of the research was evaluate burndown efficacy to Conyza spp. control in wheat crop area during the winter season, as well as at monitoring the residual effect of herbicides in soil on weed control within soybean cycle. The same experiment was conducted in two locations during the months of November 2010 and January 2011, in two locations in Rio Grande do Sul state (Condor and Estação) where have been cultivated with wheat winter crop. The treatments were composed by check without herbicide and for herbicides tank mixture. All the tank mixtures were glyphosate $720 \mathrm{~g}$ a.e. $\mathrm{ha}^{-1}$. The glyphosate was mixture with 2,4-D (402 $\mathrm{g}$ a.e. ha ${ }^{-1}$ ),

${ }_{2}^{1}$ Recebido para publicação em 24/09/2012 e aceito em 03/01/2013.

2 Professor da Faculdade Integrado de Campo Mourão, Campo Mourão, PR, Brasil. Email: <am.oliveiraneto@gmail.com>. (Autor para correspondência).

${ }^{3}$ Professores do Departamento de Agronomia da Universidade Estadual de Maringá (UEM/NAPD).

${ }^{4}$ Doutorandos do Programa de Pós-Graduação em Agronomia da Universidade Estadual de Maringá (UEM/NAPD).

${ }^{5}$ IHARA do Brasil, Sorocaba, SP, Brasil. 
diclosulam (25,2 g a.i. ha $\left.^{-1}\right)$, chlorimuron-ethyl $\left(10,20\right.$ e $25 \mathrm{~g}$ a.i. ha $\left.{ }^{-1}\right)$ and chlorimuron + flumioxazin $\left(15+50 ; 20+50 ; 25+50 ; 15+60 ; 20+60\right.$ e $25+60 \mathrm{~g}$ a.i. ha $\left.{ }^{-1}\right)$. Was evaluated the burndown control at 7, 15 and 40 DAA and the density of weeds per $\mathrm{m}^{2}$ and the growth stage of the weeds at 40 DAA. The tank mixtures of glyphosate with chlorimuron-ethyl + flumioxazin, chlorimuron-ethyl and diclosulam, independently of rates, were efficient to Conyza spp. burndown control. Treatments with glyphosate + chlorimuron-ethyl + flumioxazin were the only treatments efficient to suppress the growth of new fluxes of E. heterophylla in Condor. All the tank mixtures with chlorimuron-ethyl + flumioxazin, chlorimuron-ethyl or diclosulam suppressing the initial development of Digitaria spp., Sida rhombifolia and Ipomoea triloba in Estação.

Keywords: horseweed, Conyza spp., efficiency, tank mixture

\section{Introdução}

A buva, Conyza bonariensis e $C$. canadensis, são espécies nativas da América do Sul e do Norte, respectivamente. A primeira ocorre com grande frequência nas zonas subtropicais e temperadas da América do Sul (Kissmann \& Groth, 1999), enquanto a segunda é uma das espécies de maior distribuição do mundo, principalmente nas regiões de clima temperado ou subtropical do hemisfério norte e nas regiões subtropicais do hemisfério sul (Holm et al., 1997). No Brasil, ocorrem de forma mais frequente nas regiões Sul, Sudeste e Centro-Oeste (Kissmann \& Groth, 1999). É considerada uma das infestantes mais importantes do período de entressafra em toda a região Sul (Blainski, 2011). No Rio Grande do Sul, a buva apresenta-se como importante planta daninha infestante de lavouras de trigo, soja e milho (Vargas et al., 2007).

De acordo com Vargas et al. (2007), observou controle insatisfatório da buva em algumas lavouras no Rio Grande do Sul com uso do herbicida glyphosate. Nestas áreas o glyphosate vinha sendo utilizado na dessecação pré-semeadura com controle eficiente da buva em diferentes estádios de desenvolvimento. $\mathrm{O}$ controle insatisfatório da buva com uso do glyphosate provocou a suspeita de que biótipos resistentes a esse herbicida haviam sido selecionados, fato que foi confirmado por esses mesmos autores para Conyza bonariensis. Posteriormente também foram identificados biótipos resistentes de Conyza canadensis (Lamego \& Vidal, 2008) e de Conyza sumatrensis (Santos, 2012).

Devido à seleção dos biótipos de buva resistentes ao glyphosate, novas alternativas devem ser desenvolvidas tanto para manejar estas plantas quanto para prevenir a seleção de novos biótipos resistentes. Uma das opções é a associação de herbicidas pertencentes a diferentes mecanismos de ação (Moreira et al., 2010; Paula et al., 2011).

Dentre os principais sistemas de cultivo praticados no Sul do Brasil, a semeadura da cultura do trigo durante o inverno consiste numa das melhores opções para reduzir os níveis de infestação com buva na cultura subsequente, uma vez que promove a cobertura do solo durante o período de maior emergência da buva nesta região. Todavia, mesmo adotando este sistema, os problemas com buva não são completamente eliminados, sendo necessária a adoção do controle químico específico na dessecação de manejo que anteceda a semeadura da cultura de verão (Paula et al., 2011).

Desta maneira, o presente trabalho foi realizado com o objetivo de avaliar a eficiência de programas de dessecação de manejo com herbicidas sobre o controle de Conyza spp. em áreas cultivadas com a cultura do trigo durante o inverno, bem como avaliar o efeito destes tratamentos no controle residual de plantas daninhas na cultura da soja semeada posteriormente. 


\section{Material e Métodos}

Experimentos foram conduzidos nos municípios de Condor/RS (29 13'36,4' S, $053^{\circ} 45^{\prime} 55,4^{\prime \prime}$ O e 569 metros de altitude) e Estação/RS (2757'30,5' S, 052 ${ }^{\circ} 13$ '16,10' O e 665 metros de altitude) no período de 25/11/2010 a 05/01/2011 em áreas cultivadas sucessivamente com trigo no inverno e soja no verão. Em ambas as áreas observaram-se a ocorrência de falhas de controle da buva após a aplicação de glyphosate na dessecação de manejo e em pós-emergência da cultura da soja $\mathrm{RR}^{\circledR}$, o que é um forte indício de que havia ocorrido a seleção de biótipos resistentes ao herbicida glyphosate na área.

$\mathrm{O}$ solo da área experimental em Condor apresentava $\mathrm{pH}$ em água de 6,$0 ; 1,73 \%$ de $\mathrm{C}$; $41 \%$ de areia; $5,0 \%$ de silte e $54,0 \%$ de argila (textura argilosa). Enquanto que o solo da área experimental de Estação apresentava $\mathrm{pH}$ em água de 5,$3 ; 2,1 \%$ de $\mathrm{C} ; 19 \%$ de areia; $6,0 \%$ de silte e $75,0 \%$ de argila (textura muito argilosa).

O delineamento experimental empregado foi o de blocos ao acaso, com 12 tratamentos e quatro repetições. Os tratamentos avaliados em cada uma das localidades foram compostos por uma testemunha sem herbicida e por misturas em tanque de herbicidas, aplicados na dessecação de manejo antecedendo a semeadura direta da soja, foram aplicados no dia 25 e 26/11/2010 em Condor e Estação, respectivamente. Todas as misturas avaliadas continham glyphosate a 720 g e.a. ha ${ }^{-}$ ${ }^{1}$, na forma de sal isopropilamina. $\mathrm{O}$ glyphosate foi combinado com 2,4-D (402 g e.a. ha ${ }^{-1}$, na forma de sal dimetilamina), diclosulam $(25,2 \mathrm{~g}$ i.a. ha $\left.{ }^{-1}\right)$, chlorimuron-ethyl $(10,20$ e 25 g i.a. $\left.\mathrm{ha}^{-1}\right)$, e com chlorimuron+flumioxazin $(15+50$; $20+50 ; 25+50 ; 15+60 ; 20+60$ e $25+60$ g i.a. ha $^{-}$ $1)$.

As parcelas tinham dimensão de $5,0 \mathrm{x}$ 4,0 m $\left(20,0 \mathrm{~m}^{2}\right)$. Considerou-se como área útil para as avaliações apenas a área central de cada parcela, exceto $0,5 \mathrm{~m}$ de cada extremidade, totalizando uma área útil de $12,0 \mathrm{~m}^{2}$. As condições climáticas durante o período de condução do experimento encontram-se resumidas na Figura 1.

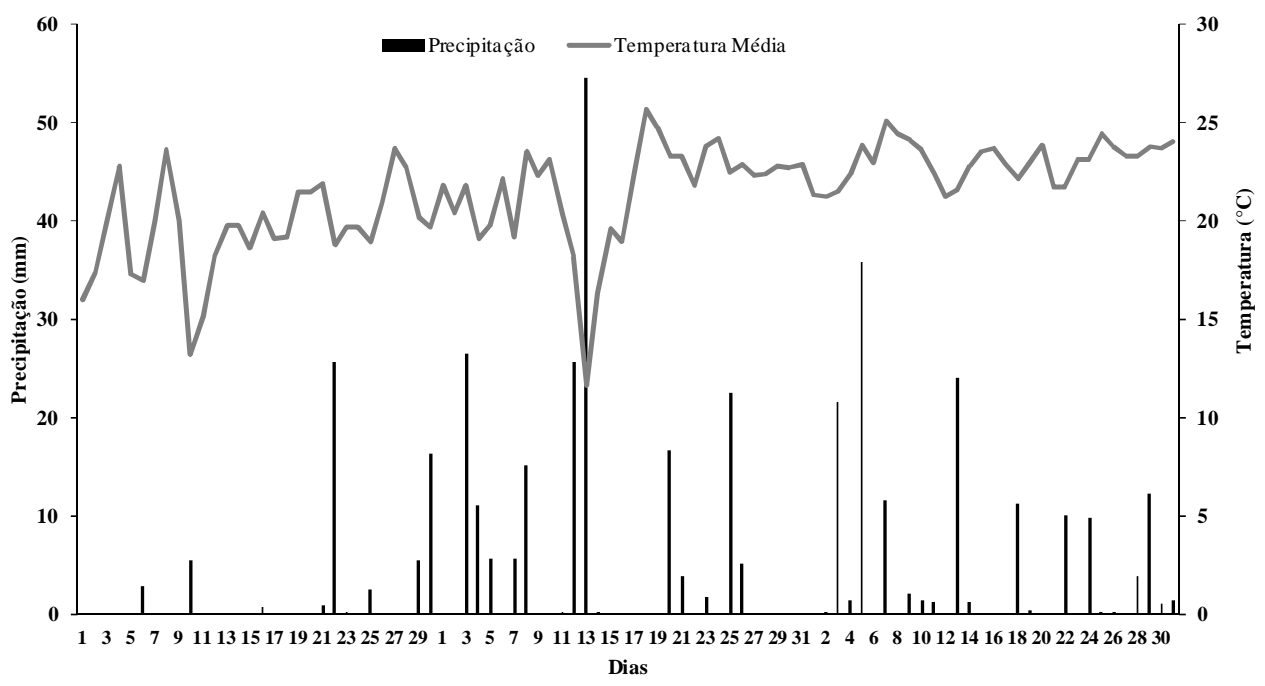

Figura 1. Precipitação pluvial diária $(\mathrm{mm})$ e temperatura média diária $\left({ }^{\circ} \mathrm{C}\right)$ verificada durante $\mathrm{o}$ período de condução do experimento (01 de Novembro de 2010 a 31 de Janeiro de 2011). Fonte: Embrapa Trigo. Mato Castelhano, RS, 2010/2011.

A planta daninha predominante no spp.) em ambas as localidades. Em Condor, a momento da dessecação foi a buva (Conyza densidade de infestação era de 14 plantas $\mathrm{m}^{-2} \mathrm{e}$ 
as plantas apresentavam altura máxima de 17 $\mathrm{cm}$; em Estação observou-se 15 plantas $\mathrm{m}^{-2} \mathrm{e}$ altura máxima de $12 \mathrm{~cm}$.

A aplicação dos tratamentos herbicidas foi realizada por meio de um pulverizador costal com pressurização por $\mathrm{CO}_{2}$, munido de barra de 1,5 m, contendo quatro pontas de pulverização do tipo TT-110.02 (0,5 m entre


proporcionando volume de aplicação equivalente a $200 \mathrm{~L} \mathrm{ha}^{-1}$.

As condições ambientais observadas na aplicação em Condor foram de temperatura do ar de $28{ }^{\circ} \mathrm{C}$, umidade relativa de $78 \%$, velocidade do vento de $2,3 \mathrm{~km} \mathrm{~h}^{-1}$, céu parcialmente nublado, solo úmido. Em Estação, as condições foram de temperatura do ar de $29{ }^{\circ} \mathrm{C}$, umidade relativa de $80 \%$, velocidade do vento de $1,7 \mathrm{~km} \mathrm{~h}^{-1}$, céu claro, solo úmido.

A cultivar utilizada na semeadura (29/11/2010) em Condor foi a Energia (14 sementes por metro linear). Em Estação (28/11/2010) utilizou-se a cultivar Nidera 4823 (13 sementes por metro linear), ambas semeadas num espaçamento de $0,45 \mathrm{~m}$ entre linhas.

Em ambas as localidades avaliaram-se a porcentagem de controle da dessecação aos 7 , 15 e 40 dias após a aplicação (DAA), onde 0 representa nenhum controle e 100 indica a morte das plantas (SBCPD, 1995). Aos 40 DAA também se avaliou a densidade de plantas daninhas por $\mathrm{m}^{2}$ e o estádio de desenvolvimento das plantas daninhas, a fim de se verificar o efeito residual de cada tratamento. As contagens foram feitas mediante a amostragem de $0,5 \mathrm{~m}^{2}$ por parcela realizada dentro da área útil das parcelas.

Cada experimento foi avaliado separadamente, onde os dados obtidos foram submetidos à análise de variância pelo teste $\mathrm{F}$ e suas médias foram comparadas pelo teste de Scott-Knott a $5 \%$ de probabilidade $(\mathrm{p}<0,05)$. Os resultados de contagem das plantas daninhas sofreram transformação de $(X+0,5)$ 0,5 conforme sugerido por Zimmermann (2004).

\section{Resultados e Discussão}

Em ambas as localidades estudadas (Condor e Estação), se observou que as misturas de glyphosate + chlorimuron-ethyl + flumioxazin, independentemente das doses, foram os únicos tratamentos que promoveram necrose foliar na buva aos 7 DAA, enquanto nas demais misturas observava apenas sinais de clorose (glyphosate com chlorimuron-ethyl ou diclosulam) ou epinastia (glyphosate $+2,4-\mathrm{D})$. Em suma, onde se adicionou o flumioxazin na mistura de glyphosate + chlorimuron-ethyl houve a aceleração no controle inicial de Conyza spp. Os herbicidas pertencentes ao grupo químico dos difeniléteres, como lactofen ou oxyfluorfen, quando misturados ao glyphosate provocam efeito de controle sinergístico. E a maior velocidade de controle pode ser atribuída à ruptura da membrana plasmática promovida pelo difeniléter que aumenta a absorção do glyphosate (Monquero, 2003). Em outros trabalhos de dessecação de manejo de plantas daninhas de forma semelhante se observou aceleração na velocidade de dessecação com a mistura de glyphosate + flumioxazin (Monquero et al., 2001; Maciel \& Constantin, 2002; Jaremtchuk et al.,2008).

De maneira geral, observou-se que os níveis de controle de buva tenderam a se igualarem à medida que o tempo avançava (Tabela 1). A disparidade na velocidade de dessecação, observada inicialmente, não persistiu nas demais avaliações e todas as misturas avaliadas foram eficazes no controle da buva. A igualdade de controle com o avanço do tempo já era esperado, pois, os herbicidas chlorimuron-ethyl, diclosulam e 2,4-D apresentam ação sistêmica, e, como consequência, a morte das plantas tratadas com estes herbicidas é lenta (Roman et al., 2007).

Tanto em Condor quanto em Estação observou-se excelentes níveis de controle final 
da buva. Indicando que os tratamentos herbicidas foram eficazes no controle desta planta daninha. Outros autores já haviam destacado a eficiência da aplicação isolada de chlorimuron-ethyl (Vargas et al., 2007) ou 2,4D (Moreira et al., 2007; Kruger et al., 2008) e da mistura de glyphosate + diclosulam (Paula et al., 2011), aplicados em pós-emergência.

Outro fator que pode ter contribuído para o bom controle da Conyza spp. é que em áreas onde se cultiva o trigo no inverno as plantas de buva apresentam menor altura e densidade após a colheita desta cultura (Paula et al., 2011). A aspersão de herbicidas sobre plantas de buva de menor altura favorece ao desempenho dos herbicidas (Oliveira Neto et al., 2010; Blainski, 2011).

Decorridos 40 DAA e por consequência 29 e 31 dias após a emergência da soja (DAE) em Condor e Estação, respectivamente, foram realizadas as avaliações de densidade e estádio de plantas daninhas emergidas (Tabelas 2 e 3).

Esta avaliação coincidiu com a época na qual foi realizada a aplicação de glyphosate para o controle de plantas daninhas em pósemergência. Assim sendo, também foi possível verificar os efeitos dos tratamentos no que concerne à situação da infestação no momento da aplicação de pós-emergência, tanto em relação à densidade de plantas emergidas e ao seu estádio de desenvolvimento.

Tabela 1. Porcentagens de controle das plantas de Conyza spp. aos 7, 15 e 40 dias após a aplicação dos tratamentos (DAA) nos municípios de Condor e Estação, RS, 2010/2011.

\begin{tabular}{|c|c|c|c|c|c|c|c|c|c|c|c|c|}
\hline \multirow{4}{*}{$\begin{array}{l}\text { Tratamentos } \\
\left(\text { g i.a. ou e.a. } \text { ha }^{-1}\right) \\
\text { chlo+flum }(720+15+50)\end{array}$} & \multicolumn{12}{|c|}{ Localidades } \\
\hline & \multicolumn{6}{|c|}{ Condor } & \multicolumn{6}{|c|}{ Estação } \\
\hline & \multicolumn{2}{|c|}{$7 \mathrm{DAA}$} & \multicolumn{2}{|c|}{15 DAA } & \multicolumn{2}{|c|}{40 DAA } & \multicolumn{2}{|c|}{$7 \mathrm{DAA}$} & \multicolumn{2}{|c|}{$15 \mathrm{DAA}$} & \multicolumn{2}{|c|}{$40 \mathrm{DAA}$} \\
\hline & 74,5 & $\mathrm{a}$ & 98,3 & $\mathrm{a}$ & 98,0 & $\mathrm{a}$ & 70,8 & $\mathrm{a}$ & 84,0 & $\mathrm{a}$ & 93,8 & $\mathrm{a}$ \\
\hline 2) gly+chlo+flum $(720+20+50)$ & 78,0 & $\mathrm{a}$ & 100,0 & $\mathrm{a}$ & 97,8 & $\mathrm{a}$ & 77,3 & $\mathrm{a}$ & 82,0 & $\mathrm{a}$ & 96,0 & $\mathrm{a}$ \\
\hline 3) gly+chlo+flum $(720+25+50)$ & 72,0 & $\mathrm{a}$ & 98,3 & $\mathrm{a}$ & 97,3 & $\mathrm{a}$ & 74,0 & $\mathrm{a}$ & 84,0 & $\mathrm{a}$ & 94,8 & $\mathrm{a}$ \\
\hline 4) gly+chlo+flum $(720+15+60)$ & 73,0 & $\mathrm{a}$ & 95,8 & $\mathrm{a}$ & 97,3 & $\mathrm{a}$ & 73,3 & $\mathrm{a}$ & 82,8 & $\mathrm{a}$ & 92,0 & $\mathrm{a}$ \\
\hline 5) gly+chlo+flum $(720+20+60)$ & 76,3 & $\mathrm{a}$ & 98,8 & $\mathrm{a}$ & 97,8 & $\mathrm{a}$ & 73,3 & $\mathrm{a}$ & 83,8 & $\mathrm{a}$ & 92,8 & $\mathrm{a}$ \\
\hline 6) gly+chlo+flum $(720+25+60)$ & 78,3 & $\mathrm{a}$ & 97,5 & $\mathrm{a}$ & 96,5 & a & 73,3 & $\mathrm{a}$ & 87,3 & $\mathrm{a}$ & 92,8 & $\mathrm{a}$ \\
\hline 7) gly+chlo $(720+15)$ & 38,8 & $\mathrm{~b}$ & 98,8 & $\mathrm{a}$ & 94,5 & $\mathrm{a}$ & 46,8 & $\mathrm{c}$ & 85,8 & $\mathrm{a}$ & 94,3 & $\mathrm{a}$ \\
\hline 8) gly+chlo $(720+20)$ & 48,8 & $\mathrm{~b}$ & 99,5 & $\mathrm{a}$ & 96,0 & $\mathrm{a}$ & 47,5 & $\mathrm{c}$ & 87,5 & $\mathrm{a}$ & 94,5 & $\mathrm{a}$ \\
\hline 9) gly+chlo $(720+25)$ & 45,0 & $\mathrm{~b}$ & 100,0 & $\mathrm{a}$ & 97,3 & a & 48,3 & $\mathrm{c}$ & 87,8 & $\mathrm{a}$ & 94,5 & $\mathrm{a}$ \\
\hline 10) gly+diclo $(720+25,2)$ & 49,3 & $\mathrm{~b}$ & 99,5 & $\mathrm{a}$ & 98,0 & a & 39,3 & $\mathrm{~d}$ & 80,0 & $\mathrm{a}$ & 96,5 & $\mathrm{a}$ \\
\hline 11) gly+2,4-D (720+402) & 47,5 & $\mathrm{~b}$ & 94,0 & $\mathrm{a}$ & 94,8 & a & 55,0 & $\mathrm{~b}$ & 75,5 & $\mathrm{a}$ & 92,5 & $\mathrm{a}$ \\
\hline 12) testemunha sem herbicida & 0,0 & $\mathrm{c}$ & 0,0 & $\mathrm{~b}$ & 0,0 & $\mathrm{~b}$ & 0,0 & $\mathrm{e}$ & 0,0 & $\mathrm{~b}$ & 0,0 & $\mathrm{~b}$ \\
\hline $\mathrm{CV} \%$ & $\overline{10,}$ & & $\overline{3,4}$ & & $\overline{1,8}$ & & $\overline{7,0}$ & & $\overline{6,0}$ & & 4,13 & \\
\hline
\end{tabular}

Obs: gly = glyphosate; chlo = chlorimuron-ethyl; flum = flumioxazin e diclo = diclosulam.

Médias seguidas de mesma letra na coluna não diferem entre si pelo teste de Scott-Knott a 5\% de probabilidade.

Nos novos fluxos de plantas daninhas que emergiram após a instalação da cultura da soja, a planta daninha predominante na área experimental foi Euphorbia heterophylla em Condor. Não foram observadas diferenças significativas $(\mathrm{p}>0,05)$ para a densidade de plantas de E. heterophylla emergidas segundo o teste de Scott-Knott (Tabela 2). Contudo, observou-se uma tendência de redução no número de plantas emergidas com a mistura de glyphosate + chlorimuron-ethyl + flumioxazin, com densidade de plantas $\leq 7,0 \mathrm{~m}^{-2}$, enquanto nos demais tratamentos (glyphosate + chlorimuron-ethyl, glyphosate + diclosulam, glyphosate $+2,4-\mathrm{D}$ e testemunha sem herbicida) os valores de densidade de plantas oscilaram de 14,5 a $35,5 \mathrm{~m}^{2}$. 
Tabela 2. Densidade de plantas daninhas emergidas de Euphorbia heterophylla (EPHHL) e densidade total de plantas emergidas (Digitaria spp. + Sida rhombifolia + Ipomoea triloba) (plantas $\mathrm{m}^{-2}$ ) aos 40 dias após a aplicação dos tratamentos (DAA) nos municípios de Condor e Estação, RS, 2010/2011.

\begin{tabular}{|c|c|c|c|c|}
\hline \multirow{3}{*}{$\begin{array}{c}\text { Tratamentos } \\
\left(\text { doses em g i.a. ou e.a. ha }{ }^{-1}\right)\end{array}$} & \multicolumn{3}{|c|}{ Localidades } & \\
\hline & \multicolumn{2}{|c|}{ Condor } & \multicolumn{2}{|c|}{ Estação } \\
\hline & \multicolumn{2}{|c|}{$\mathrm{EPHHL}^{\underline{I}}$} & \multicolumn{2}{|l|}{ Total $^{\text {II }}$} \\
\hline 1) gly + chlo + flum $(720+15+50)$ & 6,5 & $\mathrm{a}$ & 5,5 & $\mathrm{c}$ \\
\hline 2) gly + chlo + flum $(720+20+50)$ & 6,0 & $\mathrm{a}$ & 7,5 & $\mathrm{c}$ \\
\hline 3) gly + chlo + flum $(720+25+50)$ & 5,5 & a & 6,0 & $\mathrm{c}$ \\
\hline 4) gly + chlo + flum $(720+15+60)$ & 3,0 & a & 7,0 & $\mathrm{c}$ \\
\hline 5) gly + chlo + flum $(720+20+60)$ & 3,0 & a & 7,0 & $\mathrm{c}$ \\
\hline 6) gly + chlo + flum $(720+25+60)$ & 7,0 & $\mathrm{a}$ & 8,0 & $\mathrm{c}$ \\
\hline 7) gly + chlo $(720+15)$ & 15,0 & a & 12,5 & $\mathrm{~b}$ \\
\hline 8) gly + chlo $(720+20)$ & 35,5 & a & 15,5 & $\mathrm{~b}$ \\
\hline 9) gly + chlo $(720+25)$ & 34,0 & a & 11,5 & $\mathrm{~b}$ \\
\hline 10) gly + diclo $(720+25,2)$ & 24,5 & a & 8,5 & $\mathrm{c}$ \\
\hline 11) gly + 2,4-D (720 + 402) & 27,0 & a & 22,0 & $\mathrm{a}$ \\
\hline 12) testemunha sem herbicida & 14,5 & $\mathrm{a}$ & 20,0 & $\mathrm{a}$ \\
\hline $\mathrm{CV} \%$ & $\overline{63,3}$ & & 18,48 & \\
\hline
\end{tabular}

Obs: gly = glyphosate; chlo = chlorimuron-ethyl; flum = flumioxazin e diclo = diclosulam

.1/ Dados sem transformação.

Médias seguidas de mesma letra na coluna não diferem entre si pelo teste de Scott-Knott a 5\% de probabilidade. Análise estatística refere-se aos dados transformados em $(X+0,5){ }^{0,5}$

É importante destacar que a redução na densidade de plantas de E. heterophylla emergidas não implica dispensar o controle desta espécie em pós-emergência, já que essa espécie emergiu durante o período crítico de controle de plantas daninhas para a soja.

$\mathrm{O}$ fato das misturas com os herbicidas chlorimuron-ethyl e diclosulam ter apresentado elevada densidade de plantas de leiteiro pode estar relacionado ao histórico de resistência desta espécie aos inibidores da acetolacto sintase (ALS) na região. $\mathrm{Na}$ prática, isto significa que a ocorrência simultânea de biótipos de plantas daninhas resistentes aos herbicidas de diferentes mecanismos de ação, como no presente caso de buva resistente ao glyphosate e leiteiro resistente aos inibidores da ALS, a mistura de dois mecanismos de ação em uma mesma aplicação pode não ser suficiente para garantir um controle eficaz.

Em Estação, ocorreram três espécies de plantas daninhas após a instalação da soja capim-colchão (Digitaria spp.), a guanxuma (Sida rhombifolia) e a corda-de-viola (Ipomoea triloba). Entretanto, devido à distribuição irregular destas espécies nas parcelas realizou a análise da densidade total de plantas daninhas (capim-colchão + guanxuma + corda-de-viola).

Os tratamentos que tiveram a mistura de glyphosate com herbicidas de efeito residual no solo (chlorimuron-ethyl + flumioxazin, chlorimuron-ethyl e diclosulam) reduziram significativamente a densidade de plantas daninhas em relação ao tratamento com glyphosate + 2,4-D e a testemunha sem herbicida (Tabela 2).

Todavia, houve diferença na densidade de plantas daninhas entre os tratamentos com atividade residual no solo. Sendo que onde se misturou o glyphosate ao chlorimuron-ethyl + flumioxazin ou diclosulam, independentemente das doses, foi observado uma supressão na emergência de planta daninhas significativamente maior do que onde se 
misturou glyphosate $\left(720\right.$ g e.a. ha $\left.\mathrm{ha}^{-1}\right)+$ chlorimuron-ethyl (15 ou 20 ou 25 g i.a. ha ${ }^{-1}$ ) (Tabela 2). Estes resultados se assemelham com os descritos por Carbonari et al. (2008) onde o diclosulam, na dose de $25,2 \mathrm{~g} \mathrm{ha}^{-1}$, foi muito eficiente no controle de Ipomoea triloba e Sida rhombifolia, em pré-emergência. Segundo Norsworthy (2004), o flumioxazin e a mistura entre herbicidas inibidores de ALS e inibidores de Protox proporcionaram eficiente controle residual de corda-de-viola e guanxuma.

De forma geral, estes resultados corroboram com o trabalho de Jaremtchuk et al. (2009), os quais demonstraram que o flumioxazin na dose de $40 \mathrm{~g} \mathrm{ha}^{-1}$ reduziu significativamente a quantidade de plantas emergidas de Euphorbia heterophylla, Sida rhombifolia, Ipomoea triloba e Digitaria horizontalis, em solo de textura argilosa.

Com relação ao estádio de desenvolvimento das plantas daninhas por ocasião do momento de aplicação do herbicida em pós-emergência, nota-se que em Condor onde se aplicou a mistura tripla de glyphosate
+ chlorimuron-ethyl + flumioxazin as plantas de E. heterophylla se encontravam menores (maioria com 2-4 folhas verdadeiras). Em contrapartida, para as demais misturas as plantas se encontravam com 3 a 8 folhas verdadeiras (Tabela 3 ). $\mathrm{O}$ fato de haver plantas com estádios tão distintos se deve à ocorrência de dois fluxos de emergência da espécie neste período. Desta maneira, o benefício adicional proporcionado pela dessecação de manejo no sentido de atrasar a emergência de novos fluxos de infestação e, portanto, resultar em situação mais confortável para a atuação dos herbicidas em pós-emergência, foi observado apenas na mistura de glyphosate + chlorimuron-ethyl + flumioxazin, independentemente da dose.

As plantas daninhas predominantes em Estação (Digitaria spp., S. rhombifolia e $I$. triloba) tiveram o seu crescimento significativamente suprimido pelas misturas de glyphosate + chlorimuron-ethyl + flumioxazin, glyphosate + chlorimuron-ethyl e glyphosate + diclosulam (independentemente da dosagem) (Tabela 3).

Tabela 3. Estádio das plantas daninhas Euphorbia heterophylla (EPHHL), Digitaria spp. (DIG), Sida rhombifolia (SIDRH) e Ipomoea triloba (IPOTR) (folhas totalmente expandidas - EPHHL, SIDRH e IPOTR - ou perfilho por planta - DIG) aos 40 dias após a aplicação dos tratamentos (DAA) nos municípios de Condor e Estação, RS, 2010/2011.

\begin{tabular}{|c|c|c|c|c|}
\hline \multirow{3}{*}{$\begin{array}{c}\text { Tratamentos } \\
\left(\text { doses em g i.a. ou e.a. } \text { ha }^{-1}\right)\end{array}$} & \multicolumn{4}{|c|}{ Localidades } \\
\hline & \multicolumn{2}{|l|}{ Condor } & \multicolumn{2}{|l|}{ Estação } \\
\hline & $\overline{\text { EPHHL }}$ & $\overline{\text { DIG }}$ & SDRH & IPOTR \\
\hline 1) gly + chlo + flum $(720+15+50)$ & $2-4$ & $1-2$ & $2-4$ & $2-4$ \\
\hline 2) $\mathrm{gly}+$ chlo + flum $(720+20+50)$ & $2-4$ & $1-2$ & $2-4$ & $2-4$ \\
\hline 3) gly + chlo + flum $(720+25+50)$ & 3 & $1-2$ & $2-4$ & $2-4$ \\
\hline 4) gly + chlo + flum $(720+15+60)$ & $2-3$ & $1-2$ & $2-4$ & $2-4$ \\
\hline 5) $\mathrm{gly}+$ chlo + flum $(720+20+60)$ & $2-4$ & $1-2$ & $2-4$ & $2-4$ \\
\hline 6) gly + chlo + flum $(720+25+60)$ & $2-6$ & $1-2$ & $2-4$ & $2-4$ \\
\hline 7) gly + chlo $(720+15)$ & $3-8$ & $2-4$ & 3-6 & $3-6$ \\
\hline 8) gly + chlo $(720+20)$ & $4-8$ & $2-4$ & $3-6$ & $3-8$ \\
\hline 9) gly + chlo $(720+25)$ & $6-8$ & $2-4$ & $3-6$ & $3-6$ \\
\hline 10) gly + diclo $(720+25,2)$ & $3-8$ & $2-4$ & $3-6$ & $2-4$ \\
\hline 11) gly + 2,4-D (720 + 402) & $4-8$ & $>10$ & $6-8$ & $6-8$ \\
\hline 12) testemunha sem herbicida & $>8$ & $>15$ & $>12$ & $>20$ \\
\hline
\end{tabular}

Obs: gly = glyphosate; chlo = chlorimuron-ethyl; flum = flumioxazin e diclo = diclosulam. 
Contudo, a mistura tripla de glyphosate + chlorimuron-ethyl + flumioxazin destacou-se dentre os demais tratamentos pela consistência dos resultados, pois manteve o capim-colchão com 1-2 perfilhos e a guanxuma e a corda-deviola com 2-4 folhas verdadeiras, sendo estes os estádios mais favoráveis para a aplicação de pós-emergência do que estádios mais avançados como aqueles observados no tratamento com glyphosate + 2,4-D $(\geq 6$ folhas).

A utilização de sistemas de dessecação de manejo que incluam herbicidas com atividade residual no solo não altera a eficácia de dessecação de plantas daninhas e proporciona benefícios adicionais como maior velocidade de dessecação e controle residual dos novos fluxos de plantas daninhas que emergem no início do ciclo da cultura da soja. No entanto a escolha do herbicida a ser usado deve levar em conta a cultura que será semeada após a dessecação e a possível existência de biótipos resistentes na área, além das condições de cobertura e propriedades químico-físicas do solo.

\section{Conclusões}

As misturas de glyphosate + chlorimuron-ethyl + flumioxazin, glyphosate + chlorimuron-ethyl e glyphosate + diclosulam, independentemente das doses, foram eficazes para o controle de Conyza spp. na dessecação de manejo pré-semeadura da soja.

Tratamentos com glyphosate + chlorimuron-ethyl + flumioxazin foram os únicos tratamentos eficazes na supressão do crescimento de novos fluxos de $E$. heterophylla.

Todas as misturas contendo chlorimuron-ethyl + flumioxazin, chlorimuronethyl ou diclosulam suprimiram adequadamente o desenvolvimento inicial dos novos fluxos de Digitaria spp., Sida rhombifolia e Ipomoea triloba.

\section{Referências}

BLAINSKI, E. Herbicidas alternativos para o controle de Conyza spp. em diferentes estádios de desenvolvimento e monitoramento de fluxos de emergência em campo. 2011. 71f. Dissertação (Mestrado em Agronomia - Proteção de Plantas) Universidade Estadual de Maringá, Maringá, 2011.

CARBONARI, C.A. et al. Eficácia do herbicida diclosulam em associação com a palha de sorgo no controle de Ipomoea grandifolia e Sida rhombifolia. Planta Daninha, v.26, n.3, p.657-664, 2008.

HOLM, E. et al. World weeds: Natural histories and distribution. Toronto: John Wiley \& Sons, 1997. p. 226-235.

JAREMTCHUK, C.C. et al. Efeito de sistemas de manejo sobre a velocidade de dessecação, infestação inicial de plantas daninhas e desenvolvimento e produtividade da soja. Acta Scientiarum Agronomy, v.30, n.4, p.449-455, 2008 .

JAREMTCHUK, C.C. et al. Efeito residual de flumioxazin sobre a emergência de plantas daninhas em solos de textura distinta. Planta Daninha, v.27, n.1, p.191-196, 2009.

KISSMANN, K. G.; GROTH, D. Plantas infestantes e nocivas. São Paulo: Basf Brasileira, 1999. tomo II. 978 p.

KRUGER, G.R. et al. Response and survival of rosette-stage horseweed (Conyza canadensis) after exposure to 2,4-D. Weed Science, v.56, n.5, p.748-752, 2008.

LAMEGO, F. P.; VIDAL, R. A. Resistência ao glyphosate em biótipos de Conyza bonariensis e C. canadensis no Estado do Rio Grande do Sul, Brasil. Planta Daninha, v.26, n.2, p. 467471, 2008.

MACIEL, C.D.G.; CONSTANTIN, J. Mistura de flumioxazin com glyphoste e sulfosate para o manejo de plantas daninhas em citrus. 
Revista Brasileira de Herbicidas, v.3, n.2/3, p. 109-116, 2002.

MONQUEIRO, P.A.; CHRISTOFFOLETI, P.J.; SANTOS, C.T.D. Glyphosate em mistura com herbicidas alternativos para o manejo de plantas daninhas. Planta Daninha, v.19, n.3, p.375-380, 2001.

MONQUERO, P.A. Dinâmica populacional e mecanismos de tolerância de espécies de plantas daninhas ao herbicida glyphosate. 2003. 111f. Tese (Doutorado em Agronomia), Escola Superior de Agricultura Luiz de Queiroz, Piracicaba, 2003.

MOREIRA, M.S. et al. Resistência de Conyza canadensis e C. bonariensis ao herbicida glyphosate. Planta Daninha, v.25, n.1, p.157164, 2007.

NORSWORTHY, J.K. Soil-applied herbicide use in wide- and narrow-row glyphosateresistant soybean (Glycine max). Crop Protection, v.23, n.12, p.1237-1244, 2004.

OLIVEIRA NETO, A.M. et al. Manejo de Conyza bonariensis com glyphosate $+2,4-\mathrm{D}$ e amônio-glufosinate em função do estádio de desenvolvimento. Revista Brasileira de Herbicidas, v.9, n.3, p.73-80, 2010.

PAULA, J.M. et al. Manejo de Conyza bonariensis resistente ao glyphosate. Planta Daninha, v.29, n.1, p.217-227, 2011.

ROMAN, E.S. et al. Como funcionam os herbicidas: da biologia a aplicação. Passo Fundo: Berthier, 2007. 158p.

SANTOS, G. Resistência múltipla ao glyphosate e ao chlorimuron-ethyl em biótipos de Conyza sumatrensis. 2012. 79f. Dissertação (Mestrado em Agronomia/Produção Vegetal), Universidade Estadual de Maringá, Maringá. 2012.

SOCIEDADE BRASILEIRA DA CIÊNCIA DAS PLANTAS DANINHAS (SBCPD). Procedimentos para instalação, avaliação e análise de experimentos com herbicidas. Londrina: SBCPD, 1995. 42p.

VARGAS, L. et al. Buva (Conyza bonariensis) resistente ao glyphosate na região sul do Brasil. Planta Daninha, v.25, n.3, p.573-578, 2007.

ZIMMERMANN, F.J.P. Estatística aplicada à pesquisa agrícola. Santo Antônio de Goiás: Embrapa Arroz e Feijão, 2004. 402p. 